\title{
Novel heterogeneous ruthenium racemization catalyst for dynamic kinetic resolution of chiral aliphatic amines
}

\author{
Koen Adriaensen ${ }^{\mathrm{a}}$, Jannick Vercammen ${ }^{\mathrm{a}}$, Cédric Van Goethem ${ }^{\mathrm{a}}$, Samuel Eyley ${ }^{\mathrm{b}}$, Ivo Vankelecomª , Wim \\ Thielemans ${ }^{\mathrm{b}}$, Dirk De Vos ${ }^{\mathrm{a}}$ \\ a: Centre for Membrane Separations, Adsorption, Catalysis and Spectroscopy for Sustainable Solutions; Department of Microbial \\ and Molecular Systems; KU Leuven - University of Leuven; Leuven Chem\&Tech; Celestijnenlaan 200F; Post Box 2461; 3001 \\ Heverlee; Belgium. E-mail: dirk.devos@kuleuven.be
}

b: Renewable Materials and Nanotechnology Research Group, Department of Chemical Engineering, KU Leuven - University of Leuven, Campus Kulak Kortrijk, Etienne Sabbelaan 53, 8500 Kortrijk, Belgium.

\begin{abstract}
Only few dynamic kinetic resolution (DKR) systems are known for chiral aliphatic amines due to the difficult racemization of these amines. In this work, each aspect of the DKR of aliphatic amines is investigated. Various ruthenium catalysts were evaluated to increase their applicability in racemization as an alternative to established heterogeneous palladium catalysts. A heterogeneous $\mathrm{Ru}(\mathrm{III})$ on zeolite catalyst showed good activity for racemization in aprotic polar media. Next, kinetic resolution was evaluated; excellent yields (50\%) and selectivities (>99\%) were obtained in apolar solvents when employing isopentyl propionate as resolving agent. After evaluation of both components, the complete dynamic kinetic resolution of an aliphatic amine was established with good selectivity (97\%), enantiomeric excess (96\%) and a yield exceeding the kinetic resolution limit of $50 \%$.
\end{abstract}

\section{Introduction}

The amount of waste generated in the production of active pharmaceutical ingredients (API) compared to other chemical sectors is significantly higher and remains a challenge to sustainability. ${ }^{1}$ One of the reasons for this relatively high waste generation is the complexity of the APIs, which often require a multistep synthesis, stoichiometric or excess reagents, and extreme conditions leading to a poor atomeconomy. Furthermore, many APIs contain chiral centres; as a result, one of the isomers may be active while the other is not or even potentially toxic. ${ }^{2}$ When a direct asymmetric synthesis is not possible, separation of enantiomers is required. With the exception of scenarios in which the undesirable enantiomer can be repurposed, a substantial amount of waste is generated. Moreover, the separation of the reaction mixture is often arduous since the enantiomers, in most aspects, have identical chemical and physical properties.

To minimize waste generation, recycling processes have been developed. However, isolation of the desired enantiomer is often first required. ${ }^{3,4}$ Enantiomers can be separated by kinetic resolution, which utilizes an enantioselective catalyst (often an enzyme) to selectively convert one enantiomer. The resulting mixture can then be separated by conventional methods. An oxidation-reduction process is often used for recycling the undesirable enantiomer and yields again a racemic mixture, leading to a theoretically infinite number of cycles of kinetic resolution and oxidation-reduction. ${ }^{3}$ However, when these processes are combined into one step, an efficient system is created that is ideally able to provide the desired enantiomer with $100 \%$ yield and $100 \%$ enantiomeric excess. This strategy, called dynamic kinetic resolution, is therefore a valuable tool for the reduction of waste and to increase the efficiency of the pharmaceutical industry.

Many dynamic kinetic resolution (DKR) systems varying in substrate scope have been described. ${ }^{5-7}$ Despite the cost of amines, which are often produced from ketones and ammonia, relatively few DKR systems 
have been reported when compared to alcohols, especially for aliphatic amines. While research has led to efficient racemization systems for benzylic amines, ${ }^{8-11}$ aliphatic amines are less suitable substrates for these systems. Currently, reported racemization systems suffer from high catalyst loading, long reaction times, or severe incompatibility with enzymes. ${ }^{9,11,12}$ Heterogeneous Raney metal $(\mathrm{Co} / \mathrm{Ni})$ racemization catalysts are excellent for the racemization but combine poorly with the enzyme in the one-pot DKR, leading to absence of product (Raney Co) or long reaction times (Raney Ni; $96 \mathrm{~h}$ ). ${ }^{12}$ Homogeneous racemization catalysts are mainly based on Shvo's ruthenium transfer hydrogenation catalyst, ${ }^{9,13-15}$ while heterogeneous catalysts mostly consist of palladium nanoparticles supported on alkaline supports. ${ }^{8,16}$ In this contribution to the DKR of aliphatic amines, we first identify a novel heterogeneous ruthenium catalyst for amine racemization, look for appropriate kinetic resolution conditions, and finally evaluate the combination of both constituents into a functioning dynamic kinetic resolution for aliphatic amines (Figure 1).

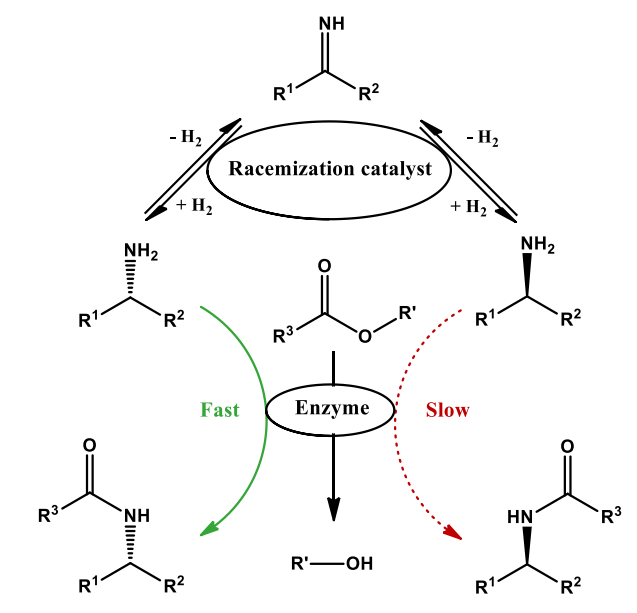

Figure 1: Schematic representation of dynamic kinetic resolution of chiral amines with esters as resolving agents.

\section{Results and discussion}

\section{Racemization of aliphatic amine}

Racemization of aliphatic amines can be achieved via radical intermediates, ${ }^{17,18}$ but is generally approached by oxidation towards an imine intermediate, followed by a non-enantioselective reduction. Therefore, a suitable racemization catalyst should be able to perform dehydrogenation (oxidation) as well as hydrogenation (reduction) of the reactant multiple times in order to obtain a racemate. Transfer hydrogenation catalysts are known to perform both processes well; for such catalysts, ruthenium is among the most used elements. ${ }^{19,20}$

\section{Catalyst screening}

Most of the known heterogeneous catalysts for benzylic amine racemization consist of supported palladium nanoparticles. ${ }^{21}$ When these heterogeneous $\mathrm{Pd}$ catalysts are applied to aliphatic amine racemization, conditions need to be significantly more severe than for benzylic amines. In the work of Kim et al., up to $12 \mathrm{~mol} \%$ catalyst is needed at a temperature of $100^{\circ} \mathrm{C} .{ }^{11} \mathrm{Apart}$ from $\mathrm{Pd}$, heterogeneous noble metal catalysts are rarely used for amine racemization, even though homogeneous Ru and Ir have been abundantly used to perform benzylic amine racemization. ${ }^{14}$ Therefore, various supported catalysts with zerovalent Ru were evaluated for racemization of an enantiopure aliphatic amine at $70{ }^{\circ} \mathrm{C}$ (Table 1). An 
ideal catalyst should convert only $50 \%$ of the $S$-enantiomer, with a selectivity of $100 \%$ for the $R$ enantiomer, resulting in a racemic mixture $(0 \%$ ee).

\begin{tabular}{|c|c|c|c|}
\hline Catalyst & $\begin{array}{c}\text { Conv. } \\
(\%)\end{array}$ & $\begin{array}{c}\text { Sel. } R- \\
\text { amine (\%) }\end{array}$ & $\begin{array}{l}e e \\
\text { (\%) }\end{array}$ \\
\hline Ideal catalyst & 50 & 100 & 0 \\
\hline $\mathrm{Ru}(0) / \mathrm{C}$ & 14.8 & 100 & 71 \\
\hline $\mathrm{Ru}(0) / \mathrm{C}$ (red.) & 9.7 & 100 & 81 \\
\hline $\mathrm{Ru}(0) / \mathrm{Al}_{2} \mathrm{O}_{3}$ & 11.4 & 99.6 & 77 \\
\hline $\mathrm{Ru}(0) / \mathrm{CaCO}_{3}$ & 2.3 & 100 & 95 \\
\hline $\mathrm{Ru}(0) / \mathrm{HAP}^{\mathrm{a}}$ & 15.3 & 98.8 & 70 \\
\hline $\mathrm{Ru}(0) / \mathrm{HSA}-\mathrm{MgAl}_{2} \mathrm{O}_{4}^{\mathrm{b}}$ & 15.3 & 91.6 & 72 \\
\hline $\mathrm{Ru}(0) / \mathrm{HSA}-\mathrm{CaAl}_{2} \mathrm{O}_{4}{ }^{\mathrm{b}}$ & 5.4 & 98.4 & 90 \\
\hline $\mathrm{Ru}(0) / \mathrm{HSA}-\mathrm{BaAl}_{2} \mathrm{O}_{4}{ }^{\mathrm{b}}$ & 10.6 & 89.5 & 81 \\
\hline
\end{tabular}

Table 1: Racemization of S-2-aminooctane with different heterogeneous catalysts. Conditions: 85 mM substrate, 5.0 mol\% catalyst loading (5.0 wt\% Ru on support), $2.0 \mathrm{~mL} \mathrm{THF,} 70{ }^{\circ} \mathrm{C}, 24 \mathrm{~h}, 1.0 \mathrm{bar} \mathrm{H}_{2}, 5.0$ bar total pressure $\left(\mathrm{N}_{2}\right)$. Conv. = conversion of S-enantiomer; Sel. = selectivity. ${ }^{a}$ : hydroxyapatite (HAP); ${ }^{b}$ : high-surface area (HSA) spinel support. ${ }^{22}$

Some racemization activity was observed for reactions where ruthenium seemed to leach out of the support to yield a dark brown-yellow colour (Entry 1,5-8). ${ }^{23}$ Since zerovalent Ru is very well retained on these supports, this observation could suggest that $\mathrm{Ru}$ is a better racemization catalyst in an ionic state. After this observation, some widely used homogeneous catalysts were screened alongside ionic ruthenium exchanged onto a zeolite support (Table 2). Homogeneous catalysts show very limited conversion and selectivity under these mild conditions (entries 1-6) while the zeolite catalyst leads to a significant drop in enantiomeric excess, coupled with a high selectivity for $R$-2-aminooctane (entries 7-8). Indeed, when homogeneous aliphatic amine racemization is reported, more severe reaction conditions seem to be required than those in Table $2\left(70{ }^{\circ} \mathrm{C}\right) .{ }^{14}$ Paetzold et al. were able to perform a complete dynamic kinetic resolution of 2-aminooctane with 4.0 mol\% of a modified Shvo-type racemization catalyst at an elevated temperature of $90{ }^{\circ} \mathrm{C}$ after 3 days to yield $85 \%$ ( $93 \%$ selectivity). ${ }^{9}$ Later, the same Bäckvall group reported that high temperatures are probably necessary to avoid coordination saturation of the amine substrate on the catalyst. ${ }^{14}$ However, elevated temperatures significantly decrease the number of suitable enzymes that can be used in a DKR system with the racemization system. Furthermore, the

\begin{tabular}{|c|c|c|c|c|c|}
\hline Catalyst & $\begin{array}{c}\text { Catalyst } \\
\text { loading (mol\%) }\end{array}$ & Conv. (\%) & $\begin{array}{c}\text { Sel. } R \text {-amine } \\
(\%)\end{array}$ & $\begin{array}{c}\text { Sel. sec. amine } \\
(\%)\end{array}$ & $e e(\%)$ \\
\hline Ideal catalyst & low & 50.0 & 100.0 & 0.0 & 0 \\
\hline$\left[\mathrm{Ru}(p \text {-cymene }) \mathrm{Cl}_{2}\right]_{2}$ & 5 & 1.9 & 60.9 & 28.1 & 98 \\
\hline $\begin{array}{l}{[\mathrm{Ru}(\mathrm{SS}-\mathrm{TsDPEN})(p-} \\
\text { cymene })(\mathrm{Py})]\left(\mathrm{BF}_{4}\right)\end{array}$ & 5 & 0.3 & 25.8 & 74.2 & $>99$ \\
\hline Shvo's catalyst ${ }^{\mathrm{a}}$ & 5 & 5.7 & 69.0 & 31.0 & 92 \\
\hline $\mathrm{Ru}(\mathrm{acac})_{3}$ & 5 & trace & 100 & 0 & $>99$ \\
\hline $\mathrm{RuCl}_{3} \cdot \mathrm{xH}_{2} \mathrm{O}$ & 5 & trace & 100 & 0 & $>99$ \\
\hline $\mathrm{RuBr}_{3} \cdot \mathrm{xH}_{2} \mathrm{O}$ & 5 & trace & 100 & 0 & $>99$ \\
\hline $\mathrm{Ru}(\mathrm{III}) / \mathrm{Y}^{\mathrm{b}}$ & 5 & 15.9 & 94.7 & 5.3 & 70 \\
\hline $\mathrm{Ru}(\mathrm{III}) / \mathrm{Y}^{\mathrm{c}}$ & 2.5 & 15.3 & 100 & 0.0 & 69 \\
\hline
\end{tabular}

Table 2: Homogeneous ruthenium catalysts compared to ionic ruthenium exchanged onto zeolite support for the racemization of S-2-aminooctane. Conditions: $85 \mathrm{mM}$ substrate, $2.0 \mathrm{~mL} \mathrm{THF}, 70{ }^{\circ} \mathrm{C}, 24 \mathrm{~h}, 1.0$ bar $\mathrm{H}_{2}, 5.0$ bar total pressure ( $\mathrm{N}_{2}$ ). ${ }^{a}$ : 1hydroxytetraphenylcyclopentadienyl(tetraphenyl-2,4-cyclopentadien-1-one)- $\mu$-hydrotetracarbonyl-diruthenium(II) $\quad b: 2.0 \quad$ wt $\%$ ruthenium on zeolite $Y$; c: 1.0 wt\% ruthenium on zeolite $Y$. 
increase in temperature also promotes side reactions with the imine intermediate. Overall, racemization at lower temperature is highly preferable in the pursuit of this DKR strategy.

Even though the $\mathrm{Ru}(\mathrm{III}) / \mathrm{Y}$ zeolite catalyst also displayed some leaching, racemization performance at the relatively low temperature of $70{ }^{\circ} \mathrm{C}$ is much higher than for any homogeneous ruthenium catalyst tested and reported so far. Furthermore, the catalyst loading was also fairly low ( $2.5 \mathrm{~mol} \%)$, especially when compared to the Pd racemization catalyst of Kim et al. (12.0 mol\%). ${ }^{11}$

\section{Influence of zeolite support}

Next, the effects of framework topology, cation composition, and silica to alumina ratio (SAR) were evaluated for different zeolite supports (Table 3 ). Ruthenium zeolite catalysts were prepared by ion exchange of a zeolite (in cationic form) with an aqueous $\mathrm{RuCl}_{3}$ solution for $24 \mathrm{~h}$, after which the catalyst was separated by centrifugation and washed thoroughly with deionized water. The targeted Ru loading of 1.0 weight percent should be possible for all SARs represented in Table 3, based on calculation of the cation exchange capacity that results from the isomorphous substitution of $\mathrm{Si}^{4+}$ by $\mathrm{Al}^{3+}$ in the lattice. Indeed, for SARs $\leq 110$, the theoretical cation exchange capacity is larger than $0.3 \mathrm{mmol} / \mathrm{g}$, or sufficient for $1.0 \mathrm{wt} \% \mathrm{Ru}$ even if threefold charge compensation is required. ICP-OES was used to determine the actual ruthenium loadings of the catalysts (see SI). The loadings were found to be around $0.9 \pm 0.1 \mathrm{wt} \%$.

\begin{tabular}{cccccccc}
\hline Support & Topology & Cation & $\begin{array}{c}\text { SAR } \\
\text { (in oxides) }\end{array}$ & Conv. (\%) & $\begin{array}{c}\text { Sel. } R \text {-amine } \\
(\%)\end{array}$ & $\begin{array}{c}\text { Sel. sec. } \\
\text { amine (\%) }\end{array}$ & ee (\%) \\
\hline ZSM-5 & MFI & $\mathrm{Na}^{+}$ & $40-48$ & 9.0 & 92.5 & 7.5 & 83 \\
MCM-22 & MWW & $\mathrm{Na}^{+}$ & 28 & 5.2 & 100 & 0.0 & 90 \\
Beta & *BEA & $\mathrm{Na}^{+}$ & 65 & 2.0 & 89.2 & 10.8 & 97 \\
Beta & *BEA & $\mathrm{Na}^{+}$ & 25 & 7.1 & 97.1 & 2.9 & 86 \\
Beta & *BEA & $\mathrm{Na}^{+}$ & 9.2 & 11.0 & 96.4 & 3.6 & 79 \\
Mordenite & MOR & $\mathrm{Na}^{+}$ & 6.5 & 20.0 & 95.6 & 4.4 & 61 \\
Zeolite L & LTL & $\mathrm{K}^{+}$ & 6 & 24.4 & 99.0 & 1.0 & 52 \\
Y & FAU & $\mathrm{Na}^{+c}$ & 60 & 1.4 & 100 & 0.0 & 97 \\
Y & FAU & $\mathrm{Na}^{+c}$ & 30 & 0.0 & 1 & $/$ & $>99$ \\
Y & FAU & $\mathrm{Na}^{+}$ & 5.1 & 15.3 & 100 & 0.0 & 69 \\
$Y^{b}$ & FAU & $\mathrm{Na}^{+}$ & 5.1 & 26.1 & 100 & 0.0 & 48 \\
$Y^{b}$ & FAU & $\mathrm{Cs}^{+}$ & 5.1 & 21.4 & 100 & 0.0 & 57 \\
\hline
\end{tabular}

Table 3: Ru(III) exchanged onto different zeolite supports (1.0 wt\%) for racemization of S-2-aminooctane. Conditions: $85 \mathrm{mM}$ substrate, 2.5 mol\% catalyst loading, $2.0 \mathrm{~mL} \mathrm{THF}, 70{ }^{\circ} \mathrm{C}, 24 \mathrm{~h}, 1.0$ bar $\mathrm{H}_{2}, 5.0$ bar total pressure ( $\mathrm{N}_{2}$ ). ${ }^{a}$ : obtained from templatefree zeolite synthesis; ${ }^{b}$ : $\mathrm{pH}$-control ( 7) during exchange of $\mathrm{Ru}(\mathrm{III})$ onto zeolite support. ${ }^{c}$ : protic zeolite exchanged to ammonium form followed by an exchange to the Na form.

Table 3 shows a trend where lower SARs result in higher activity; this is especially clear for the case of Beta zeolites where, for the same Ru content, the conversion increased as SAR decreased. A lower SAR corresponds to an increased framework negative charge, which can more easily compensate the charge of multiple charged ruthenium guests (e.g. $\mathrm{Ru}^{3+}$ ions) inside the channels. A similar trend is observed with the $Y$ zeolites, where only the catalyst based on an Al rich faujasite (SAR $=5.1$ ) appeared to give significant racemization. Note that the dealumination of Al-rich zeolites like $\mathrm{NaY}$ has profound impact on the ion exchange capacity and on the texture; this clarifies why the relation between SAR and catalytic performance is not necessarily a simple one. 
Zeolites with 10-membered ring pore systems, like ZSM-5 and MCM-22 in general are less effective than zeolites with wider, 12-membered rings, like Beta zeolites, zeolite L, Mordenite or zeolite Y. For most zeolites, the tendency for formation of undesired secondary amines is satisfactorily low. This side reaction is usually associated with the acidity needed for the condensation of an amine with an intermediate imine. ${ }^{24}$ Note that negligible Brønsted acidity is expected for zeolites in their alkaline earth forms, with exchanged $\mathrm{Na}^{+}, \mathrm{K}^{+}$or $\mathrm{Cs}^{+}$. $\mathrm{Ru}(\mathrm{III}) / \mathrm{Y}$ was chosen as racemization catalyst for further investigation due to the excellent commercial availability of the zeolite and the activity of the racemization catalyst as a whole.

\section{Evaluation of reaction parameters for $R u / Y$ catalysed amine racemization}

As discussed before, racemization of aliphatic amines is based on continuous dehydrogenationhydrogenation of the substrate. Racemization will only work when there is a dynamic equilibrium between dehydrogenation and hydrogenation, allowing both to occur side by side. Since one reaction generates hydrogen and the other consumes it, the partial hydrogen pressure is a crucial factor in successful racemization.

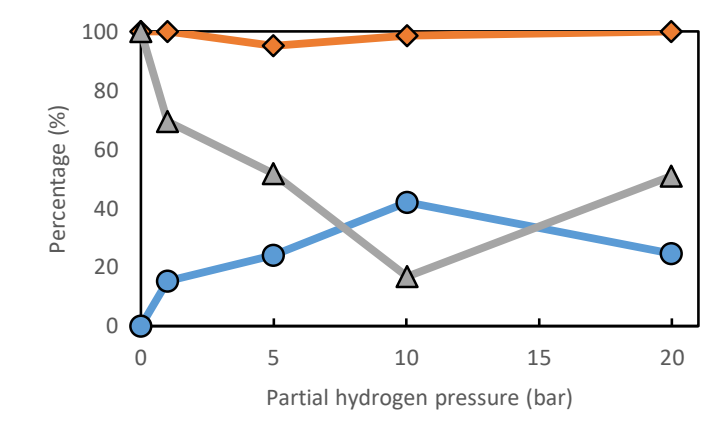

Figure 2: Influence of hydrogen pressure on conversion (0), selectivity for R-amine ( $\Delta)$ and enantiomeric excess ( $\Delta$ ) for the racemization of S-2-aminooctane with Ru(III)/Y. Conditions: $85 \mathrm{mM}$ substrate, 2.5 mol\% catalyst, $2.0 \mathrm{~mL} \mathrm{THF,} 70^{\circ} \mathrm{C}, 24 \mathrm{~h}$.

According to Figure 2, the optimal partial hydrogen pressure for the $\mathrm{Ru}(\mathrm{III}) / \mathrm{Y}$ catalyst system is around 10 bar, where a satisfactory low ee is achieved (17\%), while preserving excellent $R$-amine selectivity (98.5\%). Furthermore, racemization is also dependent on the choice of solvent (Table 4). Racemization activity generally seems better in more polar solvents; however, using alcohols as a solvent could create selectivity issues. Alcohols can be dehydrogenated towards carbonyl compounds, with which the amine will form imine products, leading to $\mathrm{N}$-alkylated amines. This is the case for isopropyl alcohol ('PrOH) and ethanol $(\mathrm{EtOH})$. When a tertiary alcohol is used as solvent $\left({ }^{\mathrm{t}} \mathrm{BuOH}\right)$, racemization performance does not improve over reaction with THF as the solvent. This may be due to the steric hindrance; alternatively, the beneficial effect of polarity may reach its optimum around a relative polarity of 0.2 . Polar solvent molecules could increase reactivity by competition in coordination to the ruthenium moiety, since amines are known to saturate coordination spheres under mild reaction conditions.

\begin{tabular}{ccccc}
\hline Solvent & $\begin{array}{c}\text { Conv. } \\
(\%)\end{array}$ & $\begin{array}{c}\text { Sel. } \\
R \text {-amine } \\
(\%)\end{array}$ & $\begin{array}{c}e e \\
(\%)\end{array}$ & $\begin{array}{c}\text { Rel. } \\
\text { polarity }\end{array}$ \\
\hline $\mathrm{MeCy}^{\mathrm{b}}$ & 12.2 & 94.9 & 77 & 0.006 \\
$\mathrm{i}^{\mathrm{Pr}} \mathrm{P}_{2} \mathrm{O}$ & 30.5 & $90.7^{\mathrm{c}}$ & 43 & 0.117 \\
$\mathrm{CPME}$ & 17.5 & 100 & 65 & $\pm 0.124^{\mathrm{d}}$ \\
\cline { 5 - 5 }
\end{tabular}




\begin{tabular}{ccccc} 
TAME & 17.5 & 89.2 & 68 & $\pm 0.124^{\text {d }}$ \\
\cline { 3 - 5 } 1,4-dioxane & 16.6 & 100 & 67 & 0.164 \\
Anisole & 4.9 & 100 & 90 & 0.198 \\
THF & $\mathbf{4 2 . 0}$ & $\mathbf{9 8 . 5}$ & $\mathbf{1 7}$ & $\mathbf{0 . 2 0 7}$ \\
tBuOH & 23.8 & 99.5 & 53 & 0.389 \\
'PrOH & 21.5 & 53.6 & 74 & 0.546 \\
EtOH & 15.7 & 23.0 & 92 & 0.654
\end{tabular}

Table 4: Solvent effect on the racemization of S-2-aminooctane with Ru(III)/Y. Conditions: $85 \mathrm{mM}$ substrate, 2.5 mol\% catalyst, $2.0 \mathrm{~mL}$ solvent, $70{ }^{\circ} \mathrm{C}, 24 \mathrm{~h}, 10.0$ bar $\mathrm{H}_{2}$. ${ }^{a}$ : relative polarity as compared to $\mathrm{H}_{2} \mathrm{O}^{25}$; ${ }^{b}$ : methylcyclohexane (MeCy) ${ }^{c}$ : side product is alkylated amine from a side reaction with the solvent; ${ }^{d}$ : relative polarity of MTBE (data on CPME and TAME were not available); e: conversion may be low due to consumption of $\mathrm{H}_{2}$ by anisole in the hydrogenation towards cyclohexyl-methyl ether.

Hydrogenation or hydrogen transfer reactions, catalysed by ionic Ru catalysts, may require an internal or external base for $\mathrm{H}_{2}$ activation as is the case for Shvo's and Noyori-lkaryia catalysts, among many others. ${ }^{26}$ Therefore, we also tested the effect of different bases on the racemization reaction in THF ( 5 equivalents with respect to the substrate)(Table 5). Carbonate bases resulted in a dramatic loss of activity, of more than $90 \%$ for $\mathrm{Na}_{2} \mathrm{CO}_{3}$ and $\mathrm{K}_{2} \mathrm{CO}_{3}$, and $80 \%$ for lithium carbonate. Sodium and potassium hydroxide displayed the same trend as the carbonate bases. Addition of $\mathrm{LiOH}$, however, did not lead to a decrease in activity; rather conversion and selectivity remained similar. Next to the quantitative effect on activity, all reactions with addition of inorganic base displayed a clear change in the colour of the solution. Without addition of base, the solution had a dark brown-yellow colour, indicating significant leaching of the Ru into solution. With addition of $\mathrm{LiOH}$, the solution became colourless (see SI for visual representation). When analysed with ICP-OES, any leaching of ruthenium species in the absence of base $( \pm 44 \%)$ was confirmed to be prevented by the addition of $\mathrm{LiOH}$ (less than $0.2 \%$ ).

\begin{tabular}{cccc}
\hline Additive & Conv. (\%) & Sel. R-amine (\%) & ee (\%) \\
\hline / & 42.0 & 98.5 & 17 \\
$\mathrm{LiOH}$ & 41.6 & 100 & 17 \\
$\mathrm{NaOH}$ & 2.8 & 100 & 94 \\
$\mathrm{KOH}$ & 1.0 & 100 & 98 \\
$\mathrm{Li}_{2} \mathrm{CO}_{3}$ & 8.8 & 100 & 82 \\
$\mathrm{Na}_{2} \mathrm{CO}_{3}$ & 1.1 & 100 & 98 \\
$\mathrm{~K}_{2} \mathrm{CO}_{3}$ & 4.2 & 100 & 92
\end{tabular}

Table 5: Effect of additives on the racemization of S-2-aminooctane with Ru(III)/Y. Conditions: $85 \mathrm{mM}$ substrate, $2.5 \mathrm{~mol} \%$ catalyst, $2.0 \mathrm{~mL} \mathrm{THF}, 70{ }^{\circ} \mathrm{C}, 24 \mathrm{~h}, 10.0 \mathrm{bar} \mathrm{H}_{2}$.

\section{Catalyst characterization}

In order to identify the active species, the $\mathrm{Ru}(\mathrm{III}) / \mathrm{Y}$ catalysts were studied by various techniques. A role for zerovalent, metallic Ru seems excluded, since pre-reduction of the catalyst under flowing $\mathrm{H}_{2}$ resulted in near-total loss of the racemization activity. In addition, XPS analysis clearly established that, before reaction, $\mathrm{Ru}(\mathrm{III})$ was the dominant valence state (Figure $3 \mathrm{~A}$ ); the signal at $281.6 \mathrm{eV}$ in the XPS $3 \mathrm{~d}$ spectrum corresponds most likely to $\mathrm{Ru}(\mathrm{III})$ species. ${ }^{27}$ TEM imaging (Figure 4) shows that ruthenium forms nanoparticles, either on the surface of the zeolite support, or close to the outer surface. This contradicts the fact that ruthenium would be exchanged as individual $\mathrm{Ru}^{3+}$ cations in the zeolite cages. Therefore, the nanoparticles must be considered as hydroxide or oxyhydroxide clusters, with an approximate $\left(\mathrm{Ru} \mathrm{u}_{\mathrm{x}}(\mathrm{OH})_{\mathrm{y}}\right)^{\mathrm{nt}}$ formula. Note that best catalytic performance was obtained when the $\mathrm{pH}$ was controlled 

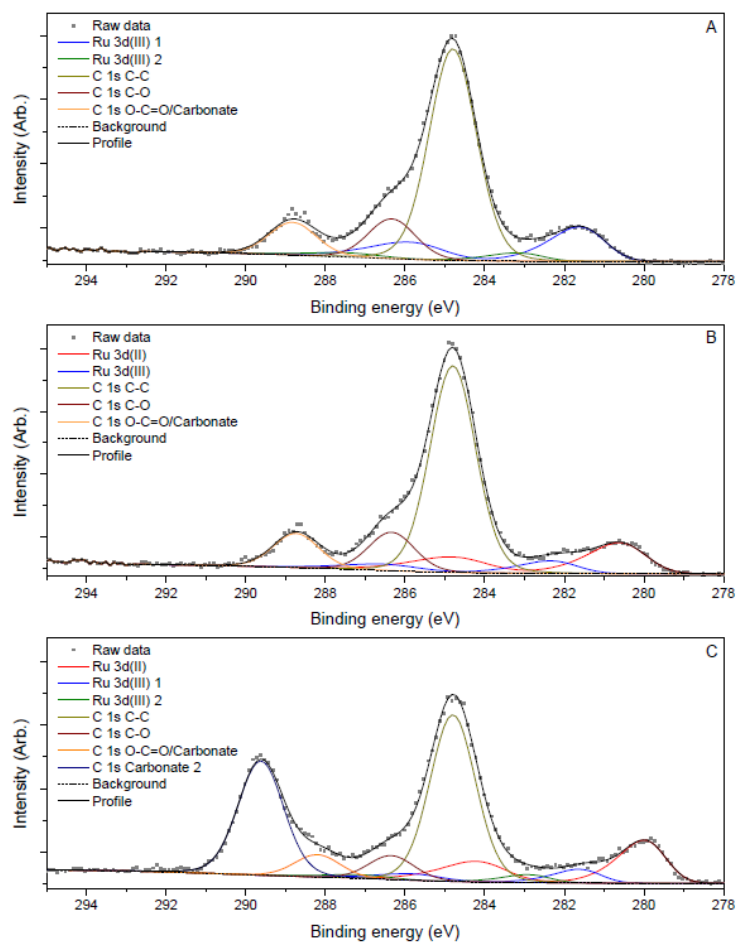

during catalyst preparation to $7.0 \pm 0.2$ with an aqueous hydroxide solution. Before reaction, nanoparticles had a size between 1.2 and $2 \mathrm{~nm}$, with a mean of $1.6 \mathrm{~nm}$ (see SI for particle size distribution). The lower size limit exactly matches the diameter of a zeolite $Y$ supercage $(1.2 \mathrm{~nm})$. This suggests that during hydroxide cluster formation, the cluster growth may be controlled by the zeolite pore; the negative charges of the zeolite pore wall could offer proper charge compensation for the ionic clusters, as an alternative to extra peripheral hydroxide ligands. The slightly larger average cluster size could imply that the clusters occasionally grow through the $0.7 \mathrm{~nm}$ window between adjacent supercages, or that parts of the clusters are located at the outer surface.

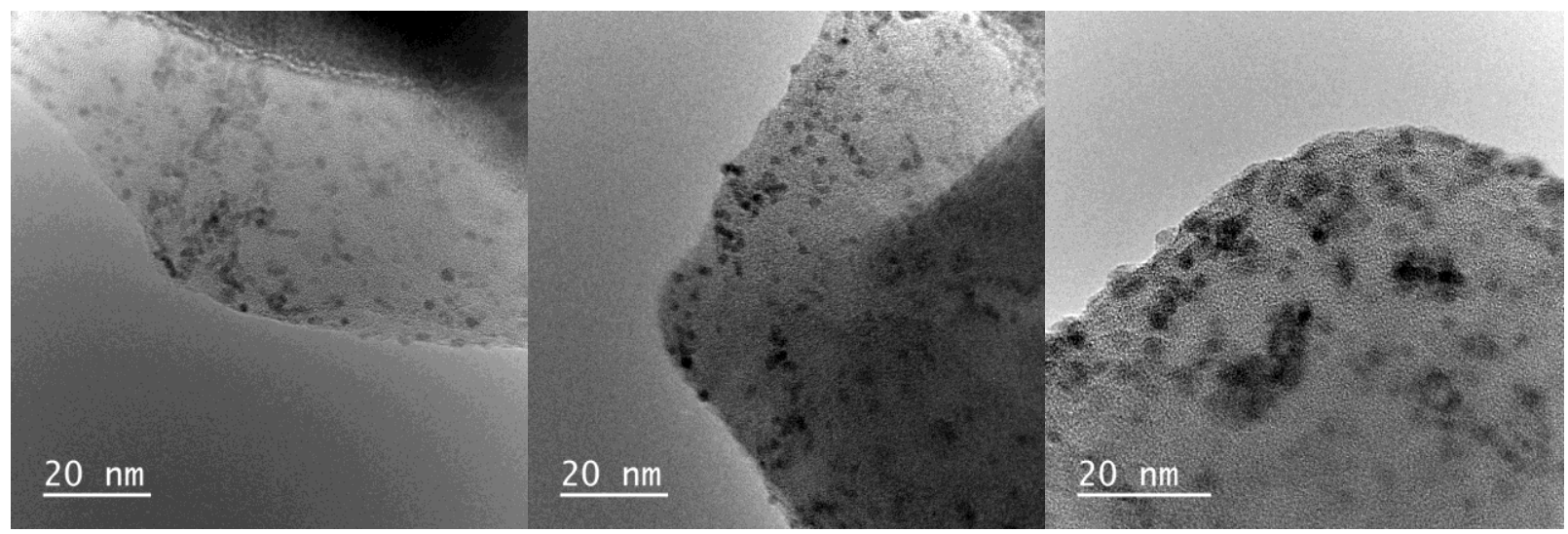

Figure 4: TEM images of Ru(III)/Y catalyst before reaction (left), after reaction without LiOH (middle) and with 5.0 equiv. of LiOH (right).

Figure 3: Ru 3d, C 1s XPS spectra of Ru(III)/Y catalyst before reaction (A), after reaction (B) and after reaction with addition of $\mathrm{LiOH}(\mathrm{C})$. 
Samples of the catalyst after reaction did not display major differences with the catalyst before reaction according to the TEM images; the nanoparticles had slightly increased in size to $2.0 \mathrm{~nm}$ and $2.3 \mathrm{~nm}$ after reaction without and with $\mathrm{LiOH}$, respectively. However, XPS analysis showed that reduced ruthenium species were present next to $\mathrm{Ru}(\mathrm{III})$ after reaction, in contrast with only $\mathrm{Ru}(\mathrm{III})$ before reaction (Figure $3 \mathrm{~B}$ and $3 \mathrm{C}$ ). The signals for ruthenium $3 \mathrm{~d}$ species shift to lower $\mathrm{eV}$, corresponding with a decrease in oxidation state best attributed to Ru(II) species according to literature. ${ }^{27}$ The signal for $\mathrm{Ru}(\mathrm{III})$ species remains and is visible as a shoulder on the larger Ru(II) signal. This suggests that both ruthenium species are present after reaction.

\section{Reaction mechanism}
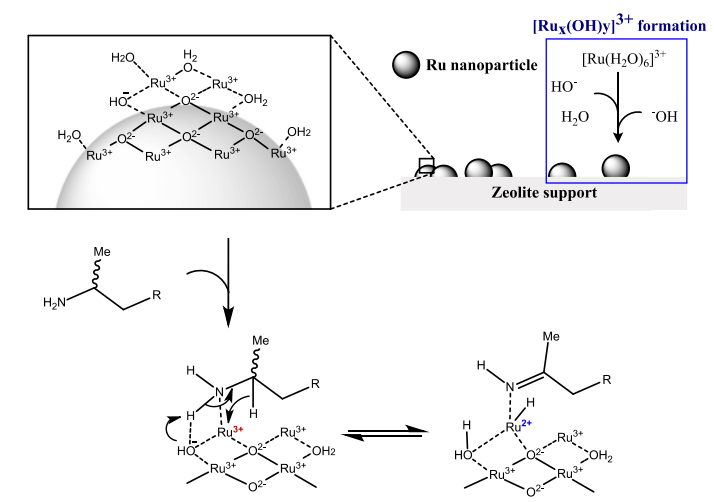

Scheme 1: Proposed reaction mechanism for racemization of aliphatic amine with $R u(I I I) / Y$ catalyst

Based on the results of catalyst characterization, we propose the reaction mechanism for racemization of aliphatic amines shown in Scheme 1. From combined TEM and XPS analysis, $\left(R u_{x}(O H)_{y}\right)^{n+}$ nanoparticles, well dispersed over the zeolite support, are proposed as the active species, their formation is represented in blue in Scheme 1. Both ionic Ru centres, either in the +II or the +III state, and the adjacent hydroxides play a role. Upon coordination of the amine substrate to the $\mathrm{Ru}$, the neighbouring basic $\mathrm{OH}^{-}$group can accept a proton from the amine, and thus induce the hydride transfer towards ruthenium. Analogous bifunctional catalysis, with Ru and an associated base, is well known from homogeneously catalysed imine transfer hydrogenation. ${ }^{28,29}$ Furthermore, a Ru-hydride has also been proposed as an intermediate in the catalytic alcohol oxidation using ionic Ru deposited on a hydroxyapatite support. ${ }^{30}$

The strong interaction between ionic $\mathrm{Ru}$ and the amine is indirectly proven by the observation that leaching only occured in the presence of the amine. In order to explain the beneficial effect of added hydroxide on the heterogeneity, one can assume that $\mu$-bridging $\mathrm{OH}^{-}$anions provide the strongest possible bonds between neighbouring Ru centres in the oxyhydroxide clusters; hence extra $\mathrm{OH}^{-}$can firmly fix the Ru ions into the cluster, without affecting their activity.

\section{Kinetic resolution of aliphatic amines}

The kinetic resolution of amines is often reported with the Candida Antarctica lipase B enzyme (CalB). ${ }^{31-}$

${ }^{33} \mathrm{CalB}$ is a robust, thermostable enzyme ( $R$-acylase) with a broad substrate scope; it can be immobilized for continuous operation or extended reuse. Here, we test the applicability of acrylic resin immobilised CalB, also commercially known as Novozyme 435, for the kinetic resolution of the aliphatic amine 2aminooctane. 


\begin{tabular}{cccccc}
\hline Solvent & Conv. (\%) & Sel. $R$-amide (\%) & Sel. N-alkyl amine (\%) & ee (\%) & Yield $R$-amide (\%) \\
\hline Ideal & $\mathbf{5 0 . 0}$ & $\mathbf{1 0 0 . 0}$ & $\mathbf{0 . 0}$ & $\mathbf{1 0 0}$ & $\mathbf{5 0}$ \\
THF & 58.1 & 56.1 & 42.5 & 96 & 33 \\
2-MeTHF & 47.9 & 45.8 & 52.4 & 92 & 22 \\
MeCN & 47.6 & 45.6 & 52.6 & 93 & 22 \\
DCM & 16.3 & 38.6 & 59.7 & 92 & 6 \\
tBuOH & 27.9 & 95.5 & 0.0 & 91 & 27 \\
n-octane & 74.0 & 71.6 & 21.2 & 82 & 49 \\
toluene & 57.8 & 94.4 & 0.0 & 89 & 50 \\
MeCy & 72.1 & 75.6 & 18.5 & 86 & 50 \\
& & & & &
\end{tabular}

Table 6: Solvent screening for the kinetic resolution of rac-2-aminooctane with isopropyl acetate ('PrOAc) as acylating agent. Conditions: $85 \mathrm{mM}$ substrate, $50.0 \mathrm{mg}$ Novozyme $435,0.6$ eq $\mathrm{PPrOAc}, 2.0 \mathrm{~mL}$ solvent, $70^{\circ} \mathrm{C}, 24 \mathrm{~h}, 5.0$ bar $\mathrm{N}_{2}$.

The stability of CalB in different organic solvents has been investigated before and it was found to decrease with increasing polarity of the solvent. ${ }^{34}$ Disruption of one of two important hydrogen bonds in the active site results in lowered activity. As shown in Table 6, using 'PrOAc as the acylating agent in combination with an apolar solvent, like toluene, results in quantitative amide formation for the kinetic resolution of aliphatic amines, while the yield for resolution in a more polar solvent, like 2-MeTHF, drops to less than half (Table 6). There seems to be no difference between protic and aprotic polar solvent here; polarity seems sufficient to disrupt a critical hydrogen bond or induce denaturation of the enzyme.

Another important aspect in kinetic resolution is the resolving agent. Both esters and carbonates have been described in various DKRs, ${ }^{35-37}$ leading to amide or carbamate products respectively. When choosing a suitable resolving agent, two important factors have to be looked at. First of all, the resolving agent should only react selectively with the reactant as facilitated by the enzyme; an uncatalyzed, aselective reaction is not desired. Secondly, the corresponding leaving group of the resolving agent should be inert after it departs; its further reaction with the product, residual substrate or with the enzyme is not 
desirable.

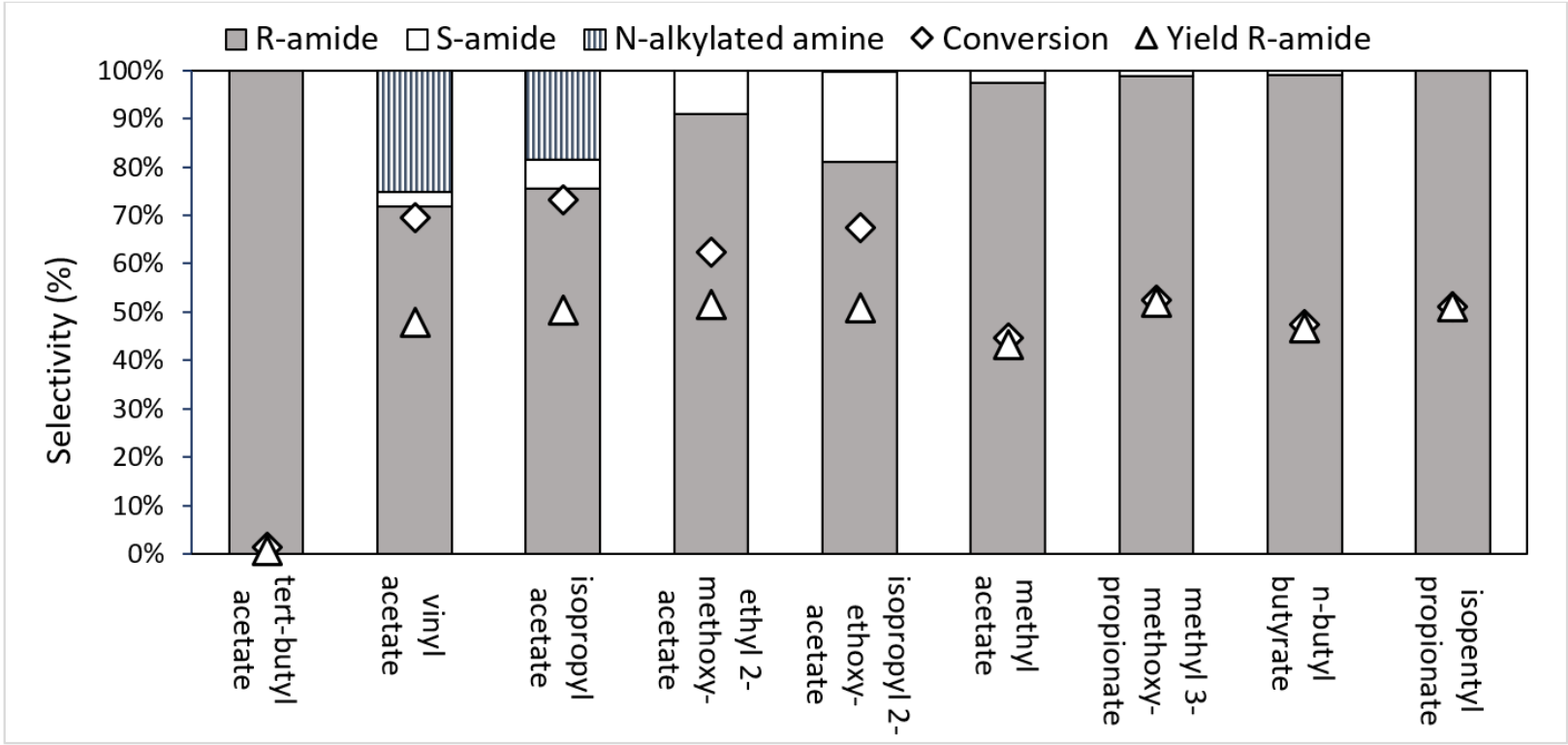

In the case of aliphatic amines, carbonate resolving agents resulted in an uncatalyzed, aselective reaction; hence esters were examined more closely as the resolving agent of choice (Figure 5). With commonly used acylating esters, like vinyl acetate and isopropyl acetate ('PrOAc), a significant alkylation side reaction resulted in $\mathrm{N}$-alkylated-2-aminooctane formation. This alkylation can be prevented when switching to 2alkoxyacetate esters as acyl donors, which react faster ${ }^{35}$ than PrOAc, enabling us to suppress the alkylation. However, both with ethyl 2-methoxyacetate and with isopropyl 2-ethoxyacetate, some aselective acylation was still observed. Finally, employing larger resolving esters, near ideal kinetic resolution conditions were achieved, with selective, enzyme controlled acylation of the substrate amine, especially for isopentyl propionate as the ester of choice.

Since CalB is a lipase, structures that mimic lipids are expected to have a better interaction with the active centre of the enzyme. The larger, more aliphatic acylating esters (such as methyl 3-methoxypropionate, butyl butyrate, or isopentyl propionate) probably fit better at the enzyme's active site than the smaller, more polar ones (such as isopropyl acetate, ethyl 2-methoxyacetate, methyl acetate ...). A small but sterically encumbered ester, like tert-butyl acetate may not fit well into the active site of the enzyme, while the small methyl ester might have too much space and consequently lose some activity.

\section{Dynamic kinetic resolution of aliphatic amine}

The dynamic kinetic resolution of aliphatic amines can be achieved by combining the findings in this work of both racemization and kinetic resolution. Since the racemization with $\mathrm{Ru}(\mathrm{III}) / \mathrm{Y}$ works best in aprotic polar solvents and kinetic resolution prefers apolar solvents (vide supra), a compromise needs to be found. Therefore, the dynamic kinetic resolution of aliphatic amines was evaluated for different solvents (Table 7). For polar solvents, like THF, the DKR is struggling to even reach the kinetic resolution limit of $50 \%$ yield. Much better results are observed when using apolar solvents, like methylcyclohexane (MeCy), exceeding the kinetic resolution limit with good selectivity (> 97\%) and enantiomeric excess (> 95\%).

\begin{tabular}{ccccc}
\hline Solvent & $\begin{array}{c}\text { Conv. } \\
(\%)\end{array}$ & $\begin{array}{c}\text { Sel. R- } \\
\text { amide (\%) }\end{array}$ & $\begin{array}{c}\text { ee } \\
(\%)\end{array}$ & $\begin{array}{c}\text { Yield } R \text { - } \\
\text { amide (\%) }\end{array}$ \\
\hline
\end{tabular}




\begin{tabular}{ccccc}
\hline Ideal & $\mathbf{1 0 0 . 0}$ & $\mathbf{1 0 0 . 0}$ & $\mathbf{1 0 0}$ & $\mathbf{1 0 0}$ \\
tBuOH & 5.9 & 98.8 & 98 & 5.8 \\
THF & 11.0 & 96.4 & 93 & 11 \\
2-MeTHF & 33.0 & 97.1 & 97 & 32 \\
n-octane & 62.2 & 94.8 & 94 & 59 \\
iPr2O & 82.0 & 73.6 & 96 & 60 \\
TAME & 63.0 & 96.3 & 95 & 61 \\
CPME & 64.7 & 97.0 & 96 & 63 \\
MeCy & $\mathbf{6 8 . 2}$ & $\mathbf{9 6 . 9}$ & $\mathbf{9 6}$ & $\mathbf{6 6}$ \\
& & & &
\end{tabular}

Table 7: Different solvents for the dynamic kinetic resolution of rac-2-aminooctane with $R u(I I I) / Y$ racemization catalyst and Novozyme 435 with isopentyl propionate as acylating agent. Conditions: $85 \mathrm{mM}$ substrate, $2.5 \mathrm{~mol} \% \mathrm{Ru}(\mathrm{III}) / \mathrm{Y}(1.0 \mathrm{wt} \%), 50.0$ mg Novozyme 435, 1.2 equiv. isopentyl propionate, $2.0 \mathrm{~mL}$ solvent, $70^{\circ} \mathrm{C}, 24 \mathrm{~h}, 10.0 \mathrm{bar} \mathrm{H}_{2}$.

The remaining, unreacted amine is enantio-enriched with the $S$-enantiomer, suggesting inefficient racemization by the ruthenium catalyst under these conditions. Even with a compromise solvent, like diisopropyl ether ( ${ }^{2} \mathrm{Pr}_{2} \mathrm{O}$ ) or cyclopentylmethyl ether (CPME), the DKR does not exceed $63 \%$ yield. Addition of base to the reaction media is harmful for the enzyme stability; product yield is far below kinetic resolution limit in case extra base is added.

Nevertheless, we have shown the unprecedented applicability of a new heterogeneous ruthenium catalyst for racemization of aliphatic amines at mild temperature and low catalyst loadings. We exceeded the kinetic resolution limit when the catalyst is combined with an enzyme in a dynamic kinetic resolution. Improvements to enzyme stability or catalyst immobilisation may further benefit this DKR system in the future.

\section{Conclusion}

In conclusion, we have found a novel heterogeneous ruthenium based catalyst for the racemization of aliphatic amines. The $\mathrm{Ru}(\mathrm{III}) / \mathrm{Y}$ catalyst can selectively racemise aliphatic amines with simple addition of 10 bars of hydrogen, at the comparatively low temperature of $70^{\circ} \mathrm{C}$. Any residual Ru leaching can be controlled by the addition of 5 equivalents of $\mathrm{LiOH}$. Racemization has been shown to be best performed in aprotic polar solvents.

Furthermore, a suitable resolving agent, viz. isopentyl propionate, was identified for kinetic resolution of the aliphatic model amine, 2-aminooctane, in order to convert one enantiomer selectively to an enantiopure amide. The enzyme performance of CalB in the kinetic resolution was studied and confirmed to be decreasing with increasing polarity of solvent.

Combination of the findings in racemization and kinetic resolution resulted in a novel dynamic kinetic resolution of aliphatic amines, exceeding the kinetic resolution limit of $50 \%$ yield with high selectivity (97\%) and enantiomeric excess (96\%).

\section{Conflicts of interest}

There are no conflicts to declare.

\section{Acknowledgements}


The authors would like to thank Simon Smolders and Carlos Marquez for assistance with XRD and ICP-OES measurements. K.A. thanks Rik Verschueren for proofreading the manuscript. D.D.V. acknowledges the FWO for research project funding, the Flemish government for long-term structural funding through the Methusalem program, and EoS (FWO-FNRS) for financial support. J.V. thanks the FWO for funding. C.V.G. and I.V. thank the Hercules fund for financial aid of project AKUL/13/19. W.T. and S.E. acknowledge financial support through the Accelerate ${ }^{3}$ project from the Interreg Vlaanderen-Nederland program and Flanders Innovation \& Entrepreneurship and from KU Leuven internal grant 3E180424. W.T. also acknowledges support from the province West-Vlaanderen for his Provincial Chair in Advanced Materials.

\section{Experimental}

All reagents and solvents were purchased from commercial sources and used as delivered unless specified.

\section{Supports:}

Hydroxyapatite and high surface area spinels were synthesized according to literature. ${ }^{22,38}$

Y zeolites, CBV-100 (SAR 5.1), CBV-720 (SAR 30) and CBV-760 (SAR 60), was obtained from Zeolyst and treated with an aqueous $1 \mathrm{M} \mathrm{NaNO}_{3}$ solution for 1 day. After stirring for 1 day at room temperature, the zeolite suspension is centrifuged and washed with deionized water (3x). CBV-720 and CBV-760 zeolites were exchanged to the ammonium form before treatment with NaNO3 by stirring the protic zeolite with 5.0 equivalent (in respect to the protic sites) of $7 \mathrm{M} \mathrm{NH} 3$ in methanol for $2 \mathrm{~h}$ at room temperature.

All other zeolite supports were treated in a similar manner as CBV-100 unless specified. Mordenite, Beta, ZSM-5 and MCM-22 zeolites were purchased from Zeocat, Sudchemie, Alsi-Penta Zeolithe GmbH and China Catalyst corporation respectively. Template-free Beta (SAR 9.2) and zeolite L synthesis was adapted from literature. ${ }^{39,40}$

TF- ${ }^{*} B E A: 0.07 \mathrm{~g} \mathrm{NaAlO}_{2}$ was dissolved in $7.56 \mathrm{~mL}$ water, followed by addition of $0.312 \mathrm{~g} \mathrm{NaOH}$. The solution was stirred for $30 \mathrm{~min}$. Next, $0.72 \mathrm{~g}$ fumed silica was added while stirring along with $0.036 \mathrm{~g}$ of seeds (zeolyst CP814C) and the mixture was stirred until a homogeneous gel was obtained. The gel was transferred to a PTFE liner and loaded into a steel autoclave. The autoclave was heated to $150{ }^{\circ} \mathrm{C}$ for 5 days, after which the suspension was filtered and washed with demineralized water. Crystals were exchanged 3 times with an aqueous $1 \mathrm{M} \mathrm{NH}_{4} \mathrm{NO}_{3}$ solution and then calcined at $450{ }^{\circ} \mathrm{C}$. ${ }^{*} \mathrm{BEA}$ topology was confirmed with XRD analysis.

Zeolite L: First, $1.582 \mathrm{~g}$ of $\mathrm{Al}(\mathrm{OH})_{3}$ (Alfa Aesar) was dispersed in a solution of $1.582 \mathrm{~g} \mathrm{KOH}$ in $5 \mathrm{ml}$ water. This mixture was stirred for 15 minutes to obtain a clear solution. A second solution of $3.7 \mathrm{mg}$ of $\mathrm{Mg}\left(\mathrm{NO}_{3}\right)_{2}$ in $15.024 \mathrm{~g}$ of Ludox HS-40 and $11.35 \mathrm{ml}$ of water was prepared and slowly added to the first solution. A homogeneous, turbid gel was formed which transformed after a few minutes of stirring to a pourable gel. After stirring for 30 minutes, the gel was transferred to a PTFE liner and inserted in a steel autoclave. After a hydrothermal treatment at $175{ }^{\circ} \mathrm{C}$ for 2 days, the solid was filtered and washed copiously with demineralized water. A white solid (3.93 g) was obtained, and dried overnight at $80{ }^{\circ} \mathrm{C}$. The resulting powder was confirmed to be a pure LTL phase after analysis by XRD.

\section{Catalysts:}

Heterogeneous $\mathrm{Ru}(0)$ catalysts were synthesized when not commercially available. $\mathrm{Ru}(0) / \mathrm{HAP}$ and $\mathrm{Ru}(0) /$ spinel were synthesized by wet impregnation of an aqueous $\mathrm{RuCl}_{3}$ solution for $5.0 \mathrm{wt} \%$ of ruthenium on support. Water was removed by stirring at room temperature until dry, after which the catalyst was 
heated to $60^{\circ} \mathrm{C}$ in an oven and left overnight. Ruthenium was reduced under hydrogen flow (150 mL $\mathrm{H}_{2} / \mathrm{min}$ ) with the following temperature program: $450^{\circ} \mathrm{C}$ max. temperature; $2.5^{\circ} \mathrm{C} / \mathrm{min}$ ramp; $5 \mathrm{~h}$ at max. temperature.

$\mathrm{Ru}(\mathrm{III})$ /zeolite catalysts were obtained by adding the zeolite support to an aqueous ruthenium solution with $\mathrm{pH}$ correction. $\mathrm{RuCl}_{3}$ hydrate (amount according to desired weight fraction) was dissolved in demineralized water by stirring. After complete dissolution and while stirring, the corresponding amount of zeolite support for the calculated weight fraction was added. After stirring for $15 \mathrm{~min}, \mathrm{pH}$ levels of the suspension were checked and adjusted to around 7 with a $0.1 \mathrm{M}$ aqueous solution of $\mathrm{NaOH}$. pH levels were checked every 10 min and adjusted until constant. Next, the suspension was left stirring at room temperature for $24 \mathrm{~h}$, after which it was centrifuged and washed thoroughly with demineralized water. The remaining solid was then dried in an oven at $60^{\circ} \mathrm{C}$.

\section{Racemization of S-2-aminooctane:}

A glass liner is loaded with a stirring bar, $2.5 \mathrm{~mol} \%$ catalyst, $28.5 \mu \mathrm{L}$ amine $(0.17 \mathrm{mmol} ; 85 \mathrm{mM}), 2.0 \mathrm{~mL}$ solvent and $26.1 \mu \mathrm{L}$ tetradecane $(0.10 \mathrm{mmol} ; 50 \mathrm{mM})$ as internal standard. The glass liner is capped with a hollow Teflon cap and placed into a stainless steel custom autoclave. Specified gas loading is applied after purging by pressurizing/depressurizing with $\mathrm{N}_{2}$. The loaded autoclave is placed in an aluminium heating block set to the desired temperature and stirred at $500 \mathrm{rpm}$. The reaction is left stirring for $24 \mathrm{~h}$, after which the autoclave is removed from the heating block and cooled in water. The autoclave is then depressurized and opened for sample recovery. Samples are taken by a syringe and filtered over a 0.20 $\mu \mathrm{m}$ PTFE filter before collection in a GC vial $(1.0 \mathrm{~mL})$. A few drops of triethylamine and acetic anhydride are added to the GC samples for better peak separation on GC.

\section{Kinetic resolution of rac-2-aminooctane:}

A glass liner is loaded with a stirring bar, $50.0 \mathrm{mg}$ Novozyme 435 (CalB immobilized on acrylic resin), 28.5 $\mu \mathrm{L}$ amine $(0.17 \mathrm{mmol} ; 85 \mathrm{mM}), 0.6$ equivalents $(0.102 \mathrm{mmol})$ resolving agent (ester), $2.0 \mathrm{~mL}$ solvent and $26.1 \mu \mathrm{L}$ tetradecane $(0.10 \mathrm{mmol} ; 50 \mathrm{mM})$ as internal standard. The glass liner is capped with a hollow Teflon cap and placed into a stainless steel custom autoclave. Specified gas loading is applied after purging by pressurizing/depressurizing with $\mathrm{N}_{2}$. The loaded autoclave is placed in an aluminium heating block set to the desired temperature and stirred at $100 \mathrm{rpm}$. Reaction is left stirring for $24 \mathrm{~h}$, after which the autoclave is removed from the heating block and cooled in water. The autoclave is then depressurized and opened for sample recovery. Samples are taken by syringe and filtered over a $0.20 \mu \mathrm{m}$ PTFE filter before collection in a GC vial $(1.0 \mathrm{~mL})$.

\section{Dynamic kinetic resolution of rac-2-aminooctane:}

A glass liner is loaded with a stirring bar, 2.5 mol\% catalyst, $50.0 \mathrm{mg}$ novozyme 435 (CalB immobilized on acrylic resin, > $5000 \mathrm{U} / \mathrm{g}), 28.5 \mu \mathrm{L}$ amine $(0.17 \mathrm{mmol} ; 85 \mathrm{mM}), 1.2$ equivalents $(0.204 \mathrm{mmol})$ resolving agent (ester), $2.0 \mathrm{~mL}$ solvent and $26.1 \mu \mathrm{L}$ tetradecane $(0.10 \mathrm{mmol} ; 50 \mathrm{mM})$ as internal standard. The glass liner is capped with a hollow Teflon cap and placed into a stainless steel custom autoclave. Specified gas loading is applied after purging by pressurizing/depressurizing with $\mathrm{N}_{2}$. The loaded autoclave is placed in an aluminium heating block set to the desired temperature and stirred at $100 \mathrm{rpm}$. Further reaction workup was performed as for the kinetic resolution (vide supra).

\section{Methods and machines:}


Conversion, selectivities, enantiomeric excesses and yields were calculated from GC data obtained with a CP-CHIRASIL-DEX CB chiral column (25m), equipped with FID detector. Tetradecane was used as internal standard and effective carbon numbers were applied. Samples were run in parallel on a GC-MS from Agilent 6890-N with a 30 m HP-5MS column and Agilent 5973 mass-spectrometer.

Leaching of ruthenium catalysts was quantified with ICP-OES using a Varian 720-ES machine equipped with a double-pass glass cyclonic spray chamber, a Sea Spray concentric glass nebulizer and a high solids torch. Samples were prepared by collection of the filtrate of reaction, removal of organics by rotary evaporation and subsequent digestion in a 3:1 solution of concentrated $\mathrm{HCl}$ and $\mathrm{HNO}_{3}$ (aqua regia). Experimental information of XRD and XPS can be found in the supplementary information.

\section{References}

P. T. Anastas and J. C. Warner, Green Chemistry: Theory and Practice, Oxford University Press, New York, 1998.

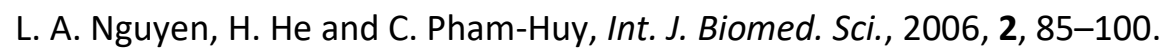
Angew. Chem. - Int. Ed., 2013, 52, 14006-14010.

M.-J. Kim, W.-H. Kim, K. Han, Y. K. Choi and J. Park, Org. Lett., 2007, 9, 1157-1159.

A. N. Parvulescu, P. A. Jacobs and D. E. De Vos, Adv. Synth. Catal., 2008, 350, 113-121.

L. K. Thalén, D. Zhao, J.-B. Sortais, J. Paetzold, C. Hoben and J.-E. Bäckvall, Chem. - Eur. J., 2009, 15, 3403-3410.

O. Verho and J. E. Bäckvall, J. Am. Chem. Soc., 2015, 137, 3996-4009.

Y. Shvo, D. Czarkie, Y. Rahamim and D. F. Chodosh, J. Am. Chem. Soc., , DOI:10.1021/ja00283a041.

A. N. Parvulescu, P. A. Jacobs and D. E. De Vos, Appl. Catal., A, 2009, 368, 9-16.

Q. Yang, F. Zhao, N. Zhang, M. Liu, H. Hu, J. Zhang and S. Zhou, Chem. Commun., 2018, 54, 14065-14068.

S. Gastaldi, S. Escoubet, N. Vanthuyne, G. Gil and M. P. Bertrand, Org. Lett., 2007, 9, 837-839.

C. Wang, X. Wu and J. Xiao, Chem. - Asian J., 2008, 3, 1750-1770.

C. Saluzzo and M. Lemaire, Adv. Synth. Catal., 2002, 344, 915-928.

Y. Ahn, S. B. Ko, M. J. Kim and J. Park, Coord. Chem. Rev., 2008, 252, 647-658.

J. Guo, H. Lou, H. Zhao, X. Wang and X. Zheng, Mater. Lett., 2004, 58, 1920-1923.

S. Agarwal and J. N. Ganguli, RSC Adv., , DOI:10.1039/c3ra47162d.

A. I. Biaglow, J. Šepa, R. J. Gorte and D. White, J. Catal., , DOI:10.1006/jcat.1995.1040.

C. Reichardt, Solvents and Solvent Effects in Organic Chemistry, Wiley, Weinheim, 2002.

C. P. Casey and J. B. Johnson, J. Am. Chem. Soc., 2005, 127, 1883-1894.

D. J. Morgan, Surf. Interface Anal., 2015, 47, 1072-1079. 
C. P. Casey, S. W. Singer, D. R. Powell, R. K. Hayashi and M. Kavana, J. Am. Chem. Soc., , DOI:10.1021/ja002177z.

29 M. Wills, Mod. Reduct. Methods, 2008, 271-296.

30 K. Kaneda, K. Mori, T. Hara, T. Mizugaki and K. Ebitani, Catal. Surv. Asia, , DOI:10.1007/s10563004-9114-3.

31 C. Ortiz, Ma. L. Ferreira, O. Barbosa, J. C. S. dos Santos, R. C. Rodrigues, Á. Berenguer-Murcia, L. E. Briand and R. Fernandez-Lafuente, Catal. Sci. Technol., 2019, 9, 2380-2420.

32 A. Tomin, G. Hornyánszky, K. Kupai, Z. Dorkó, L. Ürge, F. Darvas and L. Poppe, Process Biochem., 2010, 45, 859-865.

33 Z. Boros, D. Weiser, M. Márkus, E. Abaháziová, Á. Magyar, A. Tomin, B. Koczka, P. Kovács and L. Poppe, Process Biochem., 2013, 48, 1039-1047.

34 C. Li, T. Tan, H. Zhang and W. Feng, J. Biol. Chem., 2010, 285, 28434-28441.

35 M. Oláh, Z. Boros, G. Hornyánszky and L. Poppe, Tetrahedron, 2016, 72, 7249-7255.

36 C. E. Hoben, L. Kanupp and J. E. Bäckvall, Tetrahedron Lett., 2008, 49, 977-979.

37 A. Parvulescu, D. De Vos and P. Jacobs, Chem. Commun., 2005, 5307.

38 A. Peeters, L. Claes, I. Geukens, I. Stassen and D. De Vos, Appl. Catal., A, 2014, 469, 191-197.

39 B. Yilmaz, U. Müller, M. Feyen, S. Maurer, H. Zhang, X. Meng, F.-S. Xiao, X. Bao, W. Zhang, H. Imai, T. Yokoi, T. Tatsumi, H. Gies, T. De Baerdemaeker and D. De Vos, Catal. Sci. Technol., 2013, 3, 2580.

40 U.S., Patent 5, 242, 1993, 675. 